\title{
Article
}

\section{(Re)Making Public Campus Art: Connecting the University, Publics and the City}

Zebracki, Martin, Sumner, Ann and Speight, Elaine Available at http://clok.uclan.ac.uk/22878/

Zebracki, Martin, Sumner, Ann and Speight, Elaine ORCID: 0000-0001-52759092 (2017) (Re)Making Public Campus Art: Connecting the University, Publics and the City. Public Art Dialogue, 7 (1). pp. 6-43. ISSN 2150-2552

It is advisable to refer to the publisher's version if you intend to cite from the work. http://dx.doi.org/10.1080/21502552.2017.1288537

For more information about UCLan's research in this area go to http://www.uclan.ac.uk/researchgroups/ and search for < name of research Group>.

For information about Research generally at UCLan please go to http://www.uclan.ac.uk/research/

All outputs in CLoK are protected by Intellectual Property Rights law, including Copyright law. Copyright, IPR and Moral Rights for the works on this site are retained by the individual authors and/or other copyright owners. Terms and conditions for use of this material are defined in the policies page.

\section{CLoK}

Central Lancashire online Knowledge www.clok.uclan.ac.uk 
(RE)MAKING PUBLIC CAMPUS ART: CONNECTING THE UNIVERSITY, PUBLICS AND THE CITY

\author{
Martin Zebracki, Ann Sumner and Elaine Speight
}

\title{
INTRODUCTION
}

Public campus art in the U.K. is predominantly a postwar phenomenon and can be interpreted as artworks situated in university spaces with free access to its audience: any public users - where the multiplicity of such audience defines them as "publics": communities of interest. ${ }^{1}$ Public art's ontology of "publicness" is complex: what is "public" and who are the "publics"? The local, theme and form of art in "public" space is contested along dualist conceptions of public/private, indoor/outdoor, closed/open, permanent/temporary, decorative/interactive, past/future, space/place, online/offline, and so on and so forth. ${ }^{2}$ It may moreover span any material, digital, performative and socially engaged, practice-based work and multimedia beyond more traditional sculptural artworks. 3

This article analyses how public campus art has traditionally related to historic university agendas and campus communities, but has recently provided a platform for far-reaching public engagement beyond the campus, thus reaching new audiences. The National Co-Ordinating Centre for Public Engagement, which promotes and supports public engagement activities within U.K. universities, defines this term as:

the myriad of ways in which the activity and benefits of higher education and research can be shared with the public. Engagement is by definition a two-way process, involving interaction and listening, with the goal of generating mutual benefit. 4

Public engagement not only forms a spearhead of British universities today, it is also a major topical concern of policymaking, governance and the creative industries. ${ }^{5}$ Commentators, such as Lorna Hards, Sian Vaughan and James Williams have suggested that attention has mainly focused on the creative artistic process of commissioned sculptors/artists, rather than the specific phenomenon of public art in the campus context. ${ }^{6}$ As such, it is the article's intention to examine the motivations, methods and effects of public artworks on campus, in relation to wider concerns surrounding public engagement and the academy's role within its surrounding communities.

In the authors' roles as public art scholars and curators, this article specifically explains public art visions and engagement practices with the recent Public Art Programme supported by a Public Art Strategy (2015-present) of the University of Leeds ${ }^{7}$ vis-à-vis the long-duration public art initiative entitled In Certain Places ${ }^{8}$ (2003-present), as mediated through the University of Central Lancashire (UCLan) in Preston, U.K. The case study analyses are based on discourse analysis, qualitative evaluations and auto-ethnographic experience.

This article scrutinises public art practices across the two universities, which have involved collaborations with colleagues at other campuses and institutions who curate public art collections, too. At the intra-campus level, the article examines how public art connects broad campus communities, e.g., management, staff, students and alumni, and offers them possibilities for reflection on the university context in its material and social dimensions. In so doing, the study discusses proposals for bottom- 
up public art-led campus development as well as staff and student workshops and debates to raise awareness of the meaningfulness of art on campus. The article moreover attends to initiatives for integrating campus art into university curriculums and vocational training, and for promoting concerted departmental agendas for building a local sense of community and the promotion of "cultural sustainability". ${ }^{9}$

Beyond the campus, the article moreover examines public campus art as modus operandi for enhancing the inter-relationships between the university, city management and the creative sector, as well as between campus space users, immediate community members and the general publics. At the intersection of increasingly shrinking public budgets for the arts and culture and calls of U.K. Research and Higher Education Councils for more impact-related research and "fuller" public engagement with broad audiences and creative sectors, ${ }^{10}$ there has been a significant rise of interest among U.K. universities, city governance and creative industries for collaborative public art visions resulting in mutual benefits for the campus and the city at large. ${ }^{11}$

This article first contextualises the provenance and current challenges of curating and (re)making public campus art. The authors then critically discuss the roles, uses and alleged effects of public art across the two case-study localities at the intra-campus level and beyond the campus. The article explains how public art practice has become significantly embedded in the campus-centred cultural strategy of the University of Leeds, while it initially implicated an informal partnership between Preston City Council and UCLan in Preston - it was only in 2013 that the In Certain Places core team was exclusively based at the university. The account concludes with a critical comparative discussion of the potentialities, limitations and critiques of current public art practice on the Leeds and Preston campuses as a mediator for engaging diverse and broad publics.

\section{CREATING PUBLIC CAMPUS ART IN THE U.K.: INCARNATION}

Public art in the U.K. has seen an upsurge in the early postwar era (1950s) right at the time when "[public] sculptures were designed to bring our public spaces back to life after the Second World War as England began to repair its shattered towns and cities. This art was created for everyone, to humanise and enrich our streets, housing estates, work places, shopping centres, expanding universities and schools."12 Universities then appropriated morals of guardianship aiming to uplift ethics, improve the wellbeing of citizens (as part of the welfare state doctrine ${ }^{13}$ ) and incite enjoyment by (literally) bringing public art closer to the people in their everyday living environments. 14 The emerging U.K. campuses since the 1960 s have emphasised the both ideological and practical dialogue between public art and the built environment by integrating mostly traditional and permanent sculpture-based public artworks. This was done into (especially) portals and facades of buildings as well as by making public art an integral part of the university's ethos of campus (re)building/imagination, and since the late $20^{\text {th }}$ century the popularity of public art has become clearly reflected on campuses. ${ }^{15,16}$

Upon the advice of Historic England (officially Historic Buildings and Monuments Commission for England), which launched a postwar public art project, the British Department for Culture, Media and Sport listed 41 postwar public sculptures, including artworks at the universities of Cambridge, Greenwich, Kent, Leeds and Warwick. ${ }^{17}$ These sculptures represented the zest of the era and were recognised as iconic heritage and presented collectively in Historic England's 
exhibition Out There: Our Post War Public Art in spring 2016 at Somerset House, London. Notable campus-based public artworks include $3 B$ Series No. $1,{ }^{18}$ an abstract sculpture group by Bernard Schottlander at The University of Warwick, which has built up a substantial public art collection. ${ }^{19}$ One of two works listed in the region of Yorkshire at this time was A Celebration of Engineering Sciences, ${ }^{20}$ a façade frieze by Allan Johnson on the building of the University of Leeds' Department of Mechanical Engineering. U.K. universities rapidly expanded in a period when campus-based public art interventions were often made "to introduce some human interest into the architecture", ${ }^{21}$ a value thus recognised by these new listings.

Campus expansion since the 1960 s had particularly reconciled with a politics of material visibility. Today it is the legacy of mainly permanent, sculpture-based public art that dominates on U.K. campuses. So, universities are destined to build upon it within their curation practices and institutional reform, regeneration and expansion plans. Cultural analyist, Sara Selwood, who has written about the benefits of public art in relation to social policy, conveyed that campus development since the mid-1980s has especially involved an instrumental relationship with the then burgeoning cultural industries. However, the stakes in culture and the arts have shifted along with the move from the postwar climate of the democratisation of higher education and academic freedom towards "the wholesale 'rewiring of the state' and the push towards efficiency, effectiveness and entrepreneurialism", as embodied by the neoliberal university. ${ }^{22}$

At this juncture, the challenge is to revisit and reanimate the past while taking steps into commissioning public artworks for the future, which are meaningful to all campus users and surrounding communities. Consequently, this exercise holds challenges in gearing public art practice to both the material design and social uses of campus space. This challenge navigates along the demands of, among others, management, estates, staff, students, visitors and (prospective) audiences, as well as the needs of policymakers and authorities. Local rulings such as percent-for-art ordinances and regional Area Action Plans for alleviating any expected negative development effects directly affect the campus space. ${ }^{23,24}$ This was the case for $A$ Spire (2015), realised on the Leeds campus and discussed in the next section.

\section{CURATING PUBLIC CAMPUS ART IN THE U.K.}

While creating (mostly permanent) public art on campus was especially associated with the postwar expansion era of universities, curating campus artwork of the past particularly caught sight of universities since the turn of the century. The latter also has a direct relationship with the multidimensional user environments of higher education and research. Also, universities have increasingly approached public art as "window on the society" that they promise to serve. ${ }^{25}$ Public art has subsequently gained more visibility and importance on campuses through, among other things, public art-led curriculums, exhibitions of (degree show) artwork in public campus spaces, libraries and student union galleries, ${ }^{26}$ and beyond through student-led arts performances at public city festivals and (audio-)guided public art tours for general publics, including tourists.

Public campus art has moreover been executed through research-led artist-inresidence schemes and artist-based action research. A striking example of the latter is the Radar Artists Engage with Research programme at Loughborough University, involving contemporary art commissions for diverse campus venues in collaboration between students, staff and the wider urban community. ${ }^{27}$ 
Loughborough University, furthermore, proffered public campus art as a research impact case study to demonstrate its social and cultural benefits. In its impact statement, this study ascribed its contributions to "community cohesion", "safer urban environments" and the transformation of "the ways individuals interact in and with public spaces". ${ }^{28}$ The institution's aim was also to evidence its own institutional role as society's midfield. This was done by strategically enlisting both university actors and non-academic partners, including local authorities and cultural industries, in order to show, in the institution's own words, the "importance of public art in relation to urban regeneration and public engagement", while "shaping new models of participatory art practice - engaging the public in both the decision-making and physical production of the artwork." 29

Changing values and aesthetics of (re)developing university campuses, especially values of authority "from below" and co-production as seen in the previous Loughborough example, have involved varying approaches to the uses and purposes of public art on campus (e.g., decorative, commemorative, participative or interactive). U.K. University Public Art Programmes engage wide audiences through Audience Development planning, nurturing key communities for meaningful engagement which mediates public artworks within the context of the spaces they inhabit.

The latter goal recalls the work of art historian and critic Claire Bishop, who took democratic and hands-on principles as paramount importance to cultivating bottom-up, authentic participation in socially-engaged art practice. ${ }^{\circ}$ However, the possibilities for such participation are conditional upon persisting traditions of public art commissioning and curatorship and upon demands and stipulations by local managers and authorities, amongst others. While some universities have developed a distinct public art strategy for campus community enhancement, ${ }^{31}$ others occasionally support public art initiatives. This article deals with this difference in strategic and tactical approaches to mediating relationships between different publics, both within and outside the university. The comparative analysis of the Leeds and Preston cases deals further with this.

Connections between public art and other facets of the university campus, such as material layout, educational structure and promotional management, have been made with different intentions, with different accents and in different (sometimes fragile) alliances between university estate managers, academics, artists, architects, collectors, patrons, (commercial) art galleries, funders, staff, students, alumni, city officials, private individuals and many others. ${ }^{32}$ Here, not all universities are, as conveyed by Eleanor Nairne in her account of the relationship between the U.K. arts organisation Art Angel and the University of Warwick, equally active and successful in juggling with a holistic approach that bridges two flanks: "the fabric of university life" and "the ecology of arts organisations across the U.K.." 33 That said, many university galleries have long-term successful public funding relationships, most notably with the Arts Council England. 34

Particularly the mediating role of the university is ambiguous and therefore not always clear, as stated by artist Amelia Crouch in her response to a symposium held on the Public Art Strategy of the University of Leeds:

The approach to audiences contained within public art strategies shines a light on the current state of higher education where universities sit somewhere between being public, educational institutions and businesses focused on income generation. 35 
Crouch's argument is situated in the "multipronged" financially challenging context of British college fees and she concludes:

Universities such as Leeds have an ambition to work with artists and collections to develop audiences in line with their educational and research remit, and concurrently to improve the campus environment. Yet there is no big pot of money waiting to be spent on public art; programmes must respond strategically to current higher education agendas and potential funding streams. The risk in such a climate is that artistic value and research expertise are neglected - and that art becomes a tool to create a populist or easy to understand identity for a university audience of paying clients.

Nevertheless, there seems to be a universal quest of universities for defining the "cultural value" of public campus art. Cultural value is a highly polemic concept since John Holden published the seminal work Cultural Value and the Crisis of Legitimacy (2006). $3^{36}$ Based on this piece, Sarah Shalgosky,37 curator of The University of Warwick Art Collection, imparted that nuances in the (e)valuation of public campus art can be made along scrutinising three values: (1) the intrinsic value: the individual experiential benefit that includes self-awareness/realisation; (2) instrumental value: the social benefit that may ensue from programmes targeted on heightening inclusion, 38 education, welfare, socio-economic regeneration and community development through cooperation within and between campuses, cities, regions and countries;39 and, relatedly, (3) institutional value: the experiential benefit to a society as a whole, which reveals, in the vein of Holden, an organisational "reality" and "morality" beyond the realisation of services and products. $4^{0}$

The Curating the Campus Symposium at the University of Leeds, 11 June 2015, was a pioneering attempt to discuss the operations of public campus art's cultural values and related contributions to public art scholarship and practice across the U.K.. One of the presenters from Birmingham City University, Sian Vaughan, explained that universities, on the one hand, commission local artists to connect staff, student and wider communities by placemaking, aiming to trigger emotional and intellectual engagement, especially amongst local communities, ${ }^{41}$ thus stressing the intrinsic values of campus art. Various public art scholars take this as an important criterion of "good" public art practice that encourages situated public engagement - which is distinct from often abstract and site-generic artworks parachuted into place. ${ }^{42}$ Urban geographers Venda Pollock and Ronan Paddison conveyed that the level of placemaking through the installation of public art depends on the meanings that become associated with place, where engagement, defined as "a more invested dialogical relationship", appears to be more fruitful than somewhat passive participation soly based on, e.g., sheer consultation. 43

On the other hand, universities occasionally commission established international artists for the instrumental purpose of placemarketing, rather than placemaking. The resulting material landmarks are often claimed to represent the campus as a culturally appealing place to live, study and work - such landmarks are assumed to put the institution on the map for international visitors and entrepreneurs.44,45 While some institutions remain modest in public art investments and attending claims, most of the internationally high-ranked U.K. Russell Group universities have worked actively on collecting a substantial and cohesive body of prestigious, standalone structures as representation of their excellence in the landscape of higher research and education. This has been coupled with far-reaching 
(e)communications about the public artwork through (e.g., interpretative panels, bespoke self-guided tour leaflets, tourist board information, newsletters and university and open-day marketing). 46

The latter is usually done with an eye to instrumental values: drawing "glocal" audiences through conceptions of the university environment as a cultural hotspot. In this context, universities have particularly employed public art trails to fulfil their mission to cooperate with non-university partners, such as city departments and primary schools, 47,48 and thereby connecting themes and concerns of local, regional and international universities, arts centres, museums and (university) libraries. 49

Consequently, universities may not merely become more inclusive towards broad audiences but also more attractive sites for investors and funders. This might, then, fit the remit of entrepreneurial competition of higher-order university management. Such remit carries a bifurcation: an interest in external stakeholders and sponsors for maintaining the university's economic sustainability and cultural liveability, $5^{\circ}$ as well as an interest in being/becoming a responsible intermediary, ${ }^{51}$ vouching for the institutional value of all kinds of cultural and artistic activities on campus. Although this dual goal is generally high up on the agenda, universities are living on extremely marginal budgets to preserve the cultural and artistic values versus the economic ones. $5^{2}$

\section{CURRENT CHALLENGES}

Despite any percent-for-art stipulations, much creativity is involved in universities' delivery of high-quality and academically informed artistic output, whilst rendering account for the very diverse responsibilities and agendas of research, education and public impact. This role of campus art-making becomes even more complex by concurrently upholding the integrity of all actors involved,53 ensuring a democratic decision-making process, and meeting pressing objectives of social inclusivity. 54,55

The emphasis on enhancing social inclusivity on university agendas since the 2000 s can be an especially challenging exercise, depending on specific potentials of material design and the social composition of campus spaces - matters on which public art scholarship is especially lacking. Some multi-campus universities such as Birmingham City University are dispersed over the city and as such have highly heterogeneous end users. Other U.K. universities are rather more single-campus based and socially homogeneous, especially the self-referred "student bubble" of Loughborough and many of those that have just turned 50 years, such as the universities of Bath and York. Moreover, Blake Gumprecht, who has written about the U.S. university campus as a public space embedded in towns, argued that small-city campuses appear to be more "open and inviting" than metropolitan campuses that face a high demand for facilities and substantial security issues and, hence, limits to public access. 56

Crouch asserted that many universities have nevertheless tried to keep general publics at distance. ${ }^{57}$ For all that, publics have now been purposively invited to "couse" the campus environment on an everyday basis 58 in contexts of art, culture, sports, food and botany (as witness the rise of sustainable gardening). In these various contexts, the particular design of public art objects and practices (in material, size, duration, location, participatory features, etc.) may heighten momentary interactive experiences or, in the words of the urban design and planning scholar Quentin Stevens, the possibilities for "playfully" relating to both the built environment and "others".59 More recently, digital, online, media and mobile technologies have widened 
and deepened creative opportunities for making and engaging public campus art. These technologies, with emerging augmented reality apps in particular, pose existential challenges: how can they complement already existing artworks and to what extent do they take away the necessity of the continued upkeep and desire for permanent artwork on campus?6o

Regardless of the routes taken in their curatorial public engagement activities, universities remain occupied with perceived benefits of public campus art, the question of whom is benefitted, and how the benefits can be achieved and communicated. Understanding of public art in the educational campus environment is in need of what the environmental educator David Orr has construed as "crystallized pedagogy", 61 or place-based education. That is to say, campus environments reveal "shadow curriculums", 62 beyond the curriculums of courses, which matter to learning about how people engage with them.

But these specifics are fairly elusive. Chiming with the theorem of the cultural theorist Michel de Certeau that any space is "performative", 63 freelance art writer and researcher Beth Williamson imparted that the multifaceted nature of campus space implies its situation within multi-directional mobilities of humans and objects over time and space.64 In this light, Shalgosky65 offered the campus as a "porous environment", precisely making the (e)valuation of public campus art through the lens of diverse campus users (temporary vs. long-term students, staff, passers-by, visiting delegates, workers, and so on) and spaces (offline, online, onsite, offsite) a very complex pursuit.

All of these variables of the (re)making of public campus art indicate the transience of human experience as mediated through the changing fabric of the art object - also due to an erray of extraneous practical conditions such as weathering. ${ }^{66}$ The "atemporal, cloistered space of the gallery",67 as articulated by Shalgosky, is different from encountering the value of art across open campus space. It is in this space wherein, as argued by geographer Nigel Thrift, "we have the ability to hoover up all kinds of opportunities which a conventional gallery format makes more difficult". ${ }^{6}$

The connection between the use of public art to broker such experience as well as the relationships within the university, and its role as a mediator between the campus and wider city (and perhaps the complexity of balancing the two approaches) is the crux of this article and examined further in the subsequent two case studies on the University of Leeds Public Art Strategy and the Preston-based In Certain Places public art programme.

\section{CASE STUDY: UNIVERSITY OF LEEDS PUBLIC ART STRATEGY - BRINGING REGIONAL HERITAGE INTO PUBLIC ENGAGEMENT}

\section{Introducing the action plan}

At the Curating the Campus symposium on 11 June 2015, which was attended by 70 delegates drawn from universities throughout the U.K., the University of Leeds launched a new Public Art Programme supported by a Public Art Strategy. 69 This followed an initial consultation and report by the Contemporary Art Society and the appointment of a dedicated curator to lead the initiative.70 The Contemporary Art Society was founded in the U.K. in 1910 to encourage awareness and appreciation of contemporary art and is a charity which purchases significant works of art to place in public collections throughout the country. ${ }^{71}$

After benchmarking with Birmingham, Loughborough, Newcastle and Warwick Universities, ${ }^{2}$ as well as Lorna Hards et al.'s profound research pointers about 
orientation, engagement and understanding public art on campus, 73 the University of Leeds developed a new Public Art Trail.74 This included a performance strand with a poetry theme involving commissioned poetry responses, which are regularly read in public alongside the works, and student responses to public campus artworks, which have both been published in the trail.

The Leeds campus 75 is characterised by fine red brick buildings from the central Clothworkers buildings to villas and domesticated terraces which had been adapted to academic use and major architecture from the 1960s. There are key public spaces which have gradually been pedestrianised as part of the Estates Masterplan. All public artworks on this campus are administered and cared for by the University's Stanley \& Audrey Burton Gallery, thus implying the pivotal function of this university gallery in curatorial and managerial aspects of public campus art. ${ }^{76}$ Public art has played a key role on the Leeds campus from the Eric Gill First World War Memorial Christ Chasing the Moneychangers from the Temple (1923) - which arose controversy about both its unconventional thematic subject for a war memorial (moneychangers rather than grieving angels or soldiers) and the insinuation of Leeds merchants' profiting from war77 - to recent celebrations welcoming Simon Fujiwara's A Spire (2015), discussed later.

\section{(E-)outreach}

The Strategy with "innovative programming" emphasises the cultural values ${ }^{8}$ of enhancing the interpersonal experience of students, staff, alumni, local communities and visitors (i.e. intrinsic values); of reflecting the university's academic research themes and learning activities (i.e. institutional values); and of building new and inclusive audiences through public engagement activities (i.e. instrumental values). Social media activity through dedicated Facebook and Twitter accounts and an online blog have raised the profile of the public art collection, which can be virtually browsed on the Stanley \& Audrey Burton Gallery website.79 There are also individual interpretation texts, news stories and individual selections - the Vice-Chancellor's selection proving the most popular blog post. While the Strategy aims to market the university as a campus place of cultural interest, it allows artists and members of the public, especially in regularly organised workshops, to adopt critical approaches in relation to the university as the context of their work.

The programme has developed a cohesive approach beyond campus within the city of Leeds and regionally, guided by the central ambition statement in the strategy - highlighting related instrumental values as well as wide public engagement:

Our vision is for public art to become an integrated part of both the intellectual landscape and the built environment of the University of Leeds. This will be achieved through an inspirational, integrated and connected public art programme setting a standard that can become a benchmark for public art in higher education nationally and internationally, enabling the university to take a leading role in 21st century public art practice. ${ }^{80}$

The Public Art Programme focuses on both creating new art on campus and activating existing public artworks by eliciting responses. On the latter, an advertised programme has included Public Poetry Please!, which are regular public evening workshops. Here, all the especially commissioned poems in response to public artworks on campus are read by the poets involved, including Helen Mort, Douglas 
Caster Cultural Fellow and Linda France, Teaching Fellow in the Department of English at the University of Leeds, as well as poems submitted by the public.

Lunchtime artist talks included one by Lorna Green who re-assessed her Meet, Sit and Talk (1996) site-specific installation in Chancellor's Court nearly 20 years on, culminating with Helen Mort reading a new poem from the top of one of the boulders. This displays the Public Art Strategy's aim to re-activate already existing public artworks on campus through social engagement events.

Other activities as part of the 2015 Public Art Programme ranged from art historical debates, participation in Heritage Open Days with public tours of campus by students, and various interactive workshops. For example, a tai chi workshop was organised through the University's Confucius Institute around Keith Wilson's permanent sculpture $A$ Sign for Art (2014). ${ }^{81}$

\section{Evaluation}

The Public Art Strategy's Audience Development Plan was introduced in 2015, and sought to transform the Leeds campus into a distinct cultural destination within the city, drawing wider visitors on to campus for a sculpture park type experience. The plan is therefore concerned with organising public engagement activities, including workshops, as well as conducting evaluation (especially on views from the student population which have remained overlooked so far) and attracting funding for followup engagement activities accordingly.

Over 600 people participated in the events between June and November 2015, with an increase of a third in visitor participation in the 2016 programme. Evaluation revealed many visitors had never before ventured beyond the iconic Parkinson Court Building, but now were encouraged to pick up the Public Art Trail at the Information Point in the centre of the Court and explore campus. Feedback moreover reflected how useful the trail was for parents attending open days, new students and new staff negotiating campus for the first time, as well as conference delegates with requests now forthcoming for the Public Art Trail to be part of upcoming conferences such as that for the National Health, Safety and Wellbeing Conference in April 2017.

This evaluation fed back into a workshop in January 2016 for staff, students and representatives from universities interested in joining a new Specialist Subject Network to consider the issues involved in successfully curating public art on campus from installing works, maintaining them and programming successfully around them. A workshop session analysed the strengths and weaknesses of the 2015 Public Art Trail - such as the well-received interactive poetry panels encouraging responses and feedback which was incorporated into the 2016 trail.

A new themed approach to campus was developed with the 2016 Yorkshire Year of the Textile. This looked beyond campus to regional partnerships working for delivery with established partners such as Leeds Museums \& Galleries and new ones, including Calderdale Museums, Harrogate Borough Council and the Royal Armouries. In the spring of 2016, Arts Council England, which is a national arts development and funding agency, awarded the University of Leeds Grants for the Arts funding to support this initiative - recognised as a unique programme of commissioning with public art outputs and community engagement inspired by the rich textile history of the region and the university itself. 82 The programme celebrates knit and weave traditions and synthetic fibres industrial history since the $19^{\text {th }}$ century through creative artistic responses, performances and new exhibitions across campus and the region. 83

Thus, the Public Art Strategy at Leeds overall encourages both permanent and temporary installations as well as loans to campus, continuing to "open up" (underused) campus spaces to wider audiences. This is expanded below with some 
prominent cases. These examples characterise current trends of public art practice on the Leeds campus and demonstrate how public engagement has been enacted as per the above.

\section{Vignettes: implementing the Public Art Strategy through engagement}

Saliently, the new Laidlaw Library at the university's entrance has been enhanced by the major sculpture $A$ Spire in front of the library, for which a local percent-for-art ordinance required building development costs to be spent on art. The university's commissioning committee, which included student and staff representation, selected the Berlin-based British-Japanese artist Simon Fujiwara to create this iconic feature. The artist adopted a quasi-anthropological approach to $A$ Spire (Figure 1): a beacon and totem that evokes the industries on which the university, and indeed, the city, are largely built. It was conceived by the artist as a soaring visual timeline - a skyward archaeology connecting the past and present. Tall and cylindrical in form, A Spire is the third spire between two churches at the top of a hilly street, aiming to draw attention to the site's physical qualities and creating a visually arresting moment on campus.

Figure 1. A Spire (2015) by Simon Fujiwara, which was realised at the portal of the new Laidlaw Library and as iconic gateway to the University of Leeds campus. Courtesy University of Leeds.

From the pulverised coal integrated at the base of the spire symbolising the coal on which the city's prosperity was built, to the branches and cables laid into the cast, the surface of intertwined natural and technological elements symbolises the current digital era in which organic and human-made materials merge. This also symbolises what Hards et al. have described as "art and [digital] technology collaborations" as essentials for transferring academic knowledge and impact. ${ }^{84} \mathrm{~A}$ Spire was intended as a response to the changing urban fabric of Leeds and as an ever-changing vertical landscape and the passing of time, as expressed by Fujiwara in an interview at the Strategy's launch event:

Britain shifted from heavy industry and mining to a state of almost complete immaterial history - entertainment services, education. Leeds exemplifies this shift. Once a city of " 100 chimneys" much of its industrial history has been removed and a new post-globalised urbanism flourishes. I wanted to respond to the city's image as well as the library's function as both a place for learning - often through new media rather than books and make an object that would stand as a modern relic, catalysing and combining elements of the city's past and possible future. ${ }^{85}$

The Public Art Strategy's public engagement activities attracted members of the public, staff members and especially student and alumni communities. Student placements and a paid Public Art Intern have supported the programme and students have been actively encouraged to attend public events - the team being aware that elsewhere in the U.K., as argued by Hards et al., students have remained unvoiced in investigations of universities' uses of public art. ${ }^{86}$

Whether Fujiwara's work was a spire or a chimney, and what this meant for the place, city and region, was debated at the Public Poetry Please! event as a result of a poem submitted by a member of the public. In so doing, the rich local industrial heritage - as well as Fujiwara's play on words with A Spire and the aspirations of 
education in a new world where universities are now major city employers, or if it may "commercial enterprises" 87 - were re-visited through verse and public participation.

Other public workshops over 2015-6 which were inspired by $A$ Spire included origami and clay responses and the Landscape of the Body workshop by the choreographer Gerry Turvey (Figure 2). The latter included guided exercises and individual choreographed reactions drawing on sensory experiences and body movement. Another event was Power Walk (2016) that began with tactile warmingup exercises exploring the surface of $A$ Spire and the histories it conveyed. One oftcommented aspect of the artwork during the events was $A$ Spire's varied surface texture and the tactile response of the public generally, who it was observed often felt the work and then read the interpretative label. Plans for 2017 include the Wellbeing Trail in cooperation with Turvey to create regular movement workshops. This will involve individual exercises inspired by each artwork and yoga workshops.

Figure 2. Landscapes of the Body (2016) choreographed Gerry Turvey, which triggered tactile engagements with Fujiwara's $A$ Spire among its participants to develop an embodied understanding of Leeds' industrial history. Courtesy Gerry Turvey/TurveyWorld.

Performance responses prominently figure in the Yorkshire Year of the Textile programme that explicitly invites wide audiences, and the sometimes overlooked student population in particular, into the university's public art practice - while reactivating the historical cultural legacy of the university, city and region.-The textile theme is particularly relevant at Leeds given that the university's origins lie partly in the Yorkshire College of Science, founded in 1874 amid concerns by the local wool and textile industries at the threat posed by new continental technologies. Later in the 2oth century, Yorkshire played a key role in the Synthetic Fibres Revolution and the university opened, in 1956, its own cutting edge Man-Made Fibres Building (now called Clothworkers South Building), adorned by Mitzi Cunliffe's sculpture of the same name (Figure 3) from which the Yorkshire Year of the Textile programme has drawn considerable inspiration.

Figure 3. Mitzi Cunliffe newly conserved Man-Made Fibres (1956), ornamental sculpture atop the middle of Clothworkers South Building (see Figure 4 for context). Courtesy University of Leeds.

Inspired by Mitzi Cunliffe's eponymous sculpture, Man-Made Fibres, the Yorkshire Year of the Textile was actually launched on the 6oth anniversary of this sculpture - on 29 June 2016, 60 years to the day after the DU.K.e of Edinburgh and the Princess Royal opened the building attracting worldwide publicity in 1956. On the anniversary, there was a public site-specific dance response by TurveyWorld 88 (Figure 4) on the steps of the main entrance alongside a symbolic opening of the main entrance using the original golden key. Gerry Turvey, who choreographed the dance, conveyed through internal communication that the piece was developed through ...

improvisational play around the site, the stairs, railings, and walls, and with shape, form and idea of weaving, intertwining, and use of the hands from the sculpture ... The theme of man-made-fibres was taken more directly by using large swathes of lycra fabric in which the dancers, wrapped and unwrapped themselves into sculptural forms in and around the site. The result was a journey from exploring to owning the site and enabling the audience to see the sculpture through the physicality of the dancers. 
The dance response was repeated a few days later at a workshop, discussing the innate relationship of the university with the synthetic fabrics industry of the city and region. This was embedded in the larger Yorkshire Year of the Textile programme, which employed textile research, artistic reactions and wide community engagement with public art outputs to celebrate the past and explore future challenges of manoeuvring between the academe and public - as prevalent in broader contexts of higher education and research. ${ }^{89}$ Recently, at the annual Leeds Light Night event on 7 October 2016, South Asian Arts U.K. (SAA-U.K.) performed THREAD (Figure 5), a sound and dance response to Quinten Bell's campus-based public artwork The Dreamer, exploring and increasing public awareness of the Asian workforce in the Yorkshire textile industry in the 1970 s and 80 s.

Figure 4. TurveyWorld's Man-Made Fibres: A Dance Response (2016) as part of the celebrations for the launch of the Yorkshire Year of the Textile and especially the $60^{\text {th }}$ anniversary of Mitzi Cunliffe's Man-Made Fibres (Figure 3), adorning the top of the Clothworkers South Building in front of which this performance took place. Courtesy University of Leeds.

Figure 5. THREAD (2016), a sound and dance response created by SAA-U.K. responding to Quinten Bell's The Dreamer for Leeds Night Light in Clothworkers Court, October 2016. Courtesy University of Leeds.

Another topical key output of the Yorkshire Year of the Textile programme is Texta Textens (unveiled in October 2016), a further commissioned answer to Cunliffe's Man-Made Fibres. Created by Sue Lawty in collaboration with sculptor Dan Jones and poet Helen Mort, Texta Textens is a permanent pavement piece (woven texts in stone) drawing attention to the original Cunliffe sculpture directly above on the building, which has been unnoted for many years. However, it was the subject, during 2016, of an exhibition with a catalogue, 90 and is now the focus of a new multidisciplinary research project. It moreover decorates the front cover of the 2016 Public Art Trail and is the topic of a public lecture introduced by the Leeds-based cultural theorist Griselda Pollock, 24 November 2016.

This is a salient example of how long-standing public art on the Leeds campus is repurposed for engaging members of the university and new publics within a contemporary context. Other major public engagement responses included finger-knit workshops (Lit-Knits) across the campus and region, which were a direct reference to the hands in Cunliffe's sculpture and raised a tactile, embodied understanding of the textile legacy. The workshops involved thought-provoking poems and the production of innovative hand-knitted community canopy sculptures led by artists Elizabeth Gaston and Jane Scott.

These events engaged publics on campus and beyond in the region of Yorkshire. External sites included (library) galleries, museums, community centres and fairs, such as Skipton's Yarndale festival and British Wool Week at Leeds Industrial Museum at Armley Mills - with literally hundreds of participants creating the canopies, who described the activity as relaxing and fascinating. This culminated in the Being Human Festival event Textile Threads: Hopeful Synthetics and Public Art on 17 November 2016, including final knit workshop around the theme of sustainability.

The knitted community canopy sculptures that were produced throughout Yorkshire were initially installed in the participating venues, then displayed on campus. These works, some made from wool and others from synthetic fibres, are gradually installed in trees and across grass and decorating buildings (Figure 6). As such, the university's trajectory of public engagement activities throughout the region has come full circle and opened up campus space for larger audiences. The canopies 
were celebrated and lit up for the occasion of the earlier mentioned Leeds Light Night, 7 October 2016.

The community canopies have thus materially transformed the campus. Public workshops encourage visitors to campus, students, staff and alumni to engage with, and learn about, traditional textile heritage of both the university and region. Several interventions will also reflect on the Asian workforce in the area in the 1970s and '80s and therefore the region's changing socio-ethnic profile. Yorkshire Year of the Textile will culminate with Kate Goldsworthy's Man-Re-Made Fibres, a textile response both to Cunliffe's work on campus and the university's key concern with "sustainability". There will also be a final knitted community canopy sculpture and a textile work by Elizabeth Gaston and Jane Scott, responding to chain mail as part of armour, at the Royal Armouries Museum in Leeds Dock in the city centre. In so doing, this programme will interconnect public art on campus with public art in the city of Leeds.

Figure 6. Finger-knitted community canopy sculpture on the University of Leeds campus, 2016. Photo credit: Martin Zebracki.

\section{Reflections}

The Public Art Programme has created a framework for implementing and widely engaging public campus art as well as qualitatively evaluating and gathering feedback from audience members - which reciprocally inform the strategy on site, offsite and online. Participatory debates and active co-creation at events and workshops have appeared to be especially appreciated amongst partakers and have therefore been expanded throughout the programme. Considering scarce resources for public evaluation, as well as the subjective and idiosyncratic parameters for examining what public art "does" to people, ${ }^{11}$ its remains difficult to gauge how (the production of) art on campus contributes to abstract matters such as placemaking and community building.

The Leeds Strategy shows ambition to move this area further by developing combined public engagement and (e)valuation techniques in collaboration with English Heritage and its Postwar Public Art Project, Leeds City Council and The Twentieth Century Society regionally. The university has been working in closer collaboration with these parties on a wider strategy to enhance a concerted approach to public art throughout the city of Leeds and the region of Yorkshire. This has already begun with the development of A Public Art Toolkit for commissioning in cooperation between the university and the local council of Leeds, and the publishing of the Leeds Unfold event leaflet produced at the same time as British Art Show 8. This touring exhibition provides a "vital overview" of contemporary art in the U.K., ${ }^{2}$ including a map of public art featuring in Leeds and on campus. 93

\section{CASE STUDY: IN CERTAIN PLACES, PRESTON - (RE)FORMING CAMPUS PLACE AND URBAN DEVELOPMENT}

\section{Origins and rationale}

In Certain Places is a long-term public art programme based in Preston - a small postindustrial city in the Northwest of England. The initiative, which has gradually unfolded since its inception in 2003, is ambiguous, open-ended and difficult to define. Yet the story of its progress provides a useful narrative for considering the role of public art in relation to the complex relationships between academic institutions and the cities in which they are based. Unlike many of the public art strategies developed 
by universities to engage their immediate and surrounding communities, In Certain Places largely operates "from the outside in". Established in 2003 as an informal partnership between the University of Central Lancashire (UCLan) and the councilrun Harris Museum and Art Gallery, the project's initial focus was Preston city centre and the communities it serves. The decision in 2013 to base its operations exclusively within UCLan therefore marked a new juncture for In Certain Places, which has presented new challenges and opportunities, particularly in regard to community engagement and the relationship between public art and academia.

In Certain Places was originally conceived of as a three-year programme of temporary public artworks and events, designed to pave the way for a longer term involvement in Preston's ambitious plans for the regeneration of its centre. Due to various setbacks, most notably the global financial crisis in 2007, the city's aspirations failed to materialise; however, as an independently funded project, In Certain Places persisted and evolved,94 resulting in ongoing commissions, talks and debates and its key projects comprising The People's Canopy and Practising Place, which are both analysed in this case study. 95

Freed from the imposed timescales of the defunct regeneration scheme, In Certain Places has adopted a slow burning and open-ended approach, providing artists with open briefs and extensive timescales, and holding events in which the city's decision-makers and communities creatively explored issues of art and urban development. By involving council officers, local artists, businesses and residents in all aspects of the project, In Certain Places has engendered a mutual trust and strong working relationship with Preston. As with most public-private partnerships, this was slow to develop, however by engaging people in an iterative process of testing and reflecting, the project has gradually created a culture for public art which, in the words of Preston City Council's chief executive, has become "part of the city's DNA". ${ }^{96}$

\section{Connecting the univers[c]ity}

In comparison with the strong relationship with Preston City Council, UCLan's role within In Certain Places has until recently been considerably less significant, with the university predominantly serving as a financial supporter and resource for the project. Many of In Certain Places' public talks have been hosted in its lecture theatres and a number of artworks have been created using university facilities. However, the lack of wider engagement has largely been informed by the university's strategic priorities which, in recent years, have focused upon its international operations. As well as working to attract large numbers of students from China, where it has a longestablished presence, UCLan also has a campus in Cyprus and plans for others in Thailand and Sri Lanka. As a result, until recently the university had limited visibility and involvement in the wider Preston community and the activities of In Certain Places occurred outside of its main remit.

Nevertheless, by 2013 when, for logistical reasons, In Certain Places decided to base its administrative operations exclusively at UCLan, the university had already begun to take an interest in its locality. 97 This mirrored a wider change in academic culture across the U.K., as educational policy obliged universities to make their activities relevant and accessible to publics outside of the academic sphere and to demonstrate the real-world impact of their research. $9^{8}$ To this end, UCLan supported Harris Flights (2013) (Figure 7), a temporary architectural intervention by In Certain Places and Research Design Architecture, which facilitated direct passage between the city's main square, known locally as the Flag Market and the Harris Museum and Art Gallery - and contributed to an accompanying four-week programme of over 60 cultural and community events, including performances, contemporary art 
installations, cinema screenings, workshops, demonstrations and talks by artists, university researchers and community groups. 99

As a multi-partner project, Harris Flights not only brokered connections between different communities and decision-makers within the university and wider city, but also raised possibilities around the university's role within future developments in the city centre. As Rod Dubrow-Marshall, former Pro-ViceChancellor of UCLan explained:

Physically it's an area that much of the time is empty, and through the project we have turned it into a space that's full of activity, and that people are coming to a lot more than normal. So, for a temporary period the city centre is being regenerated. The real question is how to build on that. ${ }^{100}$

As such, Harris Flights demonstrated how temporary public art could help to fulfil UCLan's impact and public engagement agendas by enhancing the interrelationships between the university, city management and local communities, via a greater engagement in Preston's cultural life. Combined with the prospect of In Certain Places' involvement within the planned redevelopment of the university campus, UCLan's new local focus therefore offered a pertinent context for the continuation of the project. It has led to new public artworks and initiatives, such as Homing, Testing Ground and Practising Place, which will be discussed later in the section.

Figure 7. Harris Flights (2013) by In Certain Places in collaboration with architectural practice Research Design. Courtesy In Certain Places with Research Design.

\section{The People's Canopy: moving beyond the dual university/city environment}

Drawing on its dual roles within the university and city, one of the first projects In Certain Places initiated following the move to UCLan was The People's Canopy (Figure 8), a mobile architectural structure designed by the Beijing-based People's Architecture Office to connect the city centre and campus. ${ }^{101}$ Separated by a busy ring road, the campus occupies a relatively compact area north of the city centre, surrounded by Victorian terraced housing - now mainly student accommodation and independent bars and cafés. With the exception of a handful of nightclubs and its retail provision, the city has little to attract students. Equally, the university has traditionally provided limited incentives for Preston residents to make the short journey to its campus. As a result, although less than half a mile away, the two sites are physically and culturally detached.

The People's Canopy was created to address this situation by encouraging greater interaction between the two locations. Informed by workshops with residents and students, and the inclement Preston weather, the canopy is a collection of foldout event shelters, which can be cycled to different locations and configured to accommodate community activities. Funded jointly by the council, university as well as the Arts Council England, the canopy functions as a temporary social space, which allows the university to host events within the city centre and provides a resource for local communities.

To mark its launch in September 2015, The People's Canopy was cycled by 50 staff and student members of the university, accompanied by a procession of local cyclists, to the Flag Market, where it formed the centrepiece of the inaugural Lancashire Encounters festival. Yet, whilst this spectacle symbolised the university's 
increased engagement with the city, the two communities failed to connect as much as anticipated. In particular, invitations to the University's staff and students to hold public talks, seminars and performances under the canopy elicited a muted response. This lack of enthusiasm has proved to be one of the main challenges of delivering In Certain Places from within the university, as it has proved difficult to develop a substantial audience amongst its immediate campus community.

Figure 8. People's Architecture Office's The People's Canopy (2015), Preston. Photo credits: Ian Tilton (above), In Certain Places (below).

Unlike the city centre, where life is played out as a series of encounters between business owners, residents, workers and civic officers, the university is a particularly hermetic environment. The lack of social spaces - which are anticipated to be addressed by the upcoming campus redevelopment - compounded by the pressurised workload of academics has created a culture in which opportunities for informal interaction and exchange are limited. In addition, the fact that many academics live in the neighbouring cities of Lancaster and Manchester means that, with a few notable exceptions, staff rarely participate within Preston's cultural life. As a result, despite its base within the university, In Certain Places continues to draw its main audience from outside of the institution.

\section{Collaborative artistic research and its challenges}

Nevertheless, whilst it may be difficult to encourage large-scale participation amongst the campus community, the move to the university has allowed In Certain Places to develop valuable working relationships. For example, Homing (2016) (Figure 9) - a GPS-enabled audio artwork by artists Jen Southern and Sam Thulin, which allows audiences to hear fragments of correspondence from Preston soldiers in WWI, dependent on their proximity to the city's Cenotaph - was developed in collaboration with researchers from UCLan's Media and Innovation Studio, with support from the Heritage Lottery Fund and Preston City Council. ${ }^{102}$ Similarly, Manual Labours (2015) - an independent research project by artists Sophie Hope and Jenny Richards supported by In Certain Places - brought researchers from the university's Institute for Research into Organisations, Work and Employment together with administrative staff to examine UCLan's employment practices. ${ }^{103}$

Figure 9. Homing (2016) by Jen Southern and Sam Thulin, Preston. Photo credits: Jen Southern and Sam Thulin.

The facilitation of such artist-academic partnerships, both within and outside of UCLan, has become an increasingly important part of the In Certain Places programme. In 2015, for example, it initiated the Testing Ground scheme to allow artists to develop their practice through access to university research, concurrently answering higher-order calls for impact and public engagement. This has led to projects such as When Is a Star a Star? (2016) by artist Bonnie Craig, developed through conversations with astrophysicist Derek Ward-Thompson. Presented at the university's science festival, this has become an ongoing endeavour, through which both parties continue to gain alternative perspectives and valuable insights into their shared areas of research. ${ }^{104}$

Interdisciplinary projects are well received and even encouraged by the university. However, one of the drawbacks of this approach is that the artwork can often be perceived as an illustrative or dissemination tool - thus stressing Holden's 
instrumental value ${ }^{105}$ - for other academic disciplines, rather than research in its own right. This is partly due to the uneasy relationships between art and academia and between practice and research. However, as artist Tone Hansen pointed out, it is also symptomatic of a preoccupation with the display or performance of knowledge across the wider cultural sector:

There is a focus on artistic production of knowledge and process ... which is, to a great extent, service and event-oriented. In this context, the artist's ability to performatively convey her knowledge becomes a commodity. ${ }^{106}$

Whilst this emphasis on artistic output and display is conducive to academic impact and public engagement agendas, it can also obscure the specificities and value of knowledge that art practice can produce. The success of In Certain Places can be attributed to its assemblage and application of various forms of knowledge - social, cultural, embodied and economic - about Preston city centre, produced through the work of artists. Yet, such knowledge, which is generated through methods that are, in the words of curator Sarat Maharaj, "less about given, handed-down procedures than about approaches that have to be thrashed out, forged again and again on the spot,"107 can be difficult to evidence within traditional academic frameworks. This resonates with Shalgosky's point that there is no blueprint for (e)valuating the social practice of public campus art ${ }^{108}$ - its hands-on practice thus requires site-specific commitments amongst its (e)valuators.

Practicing Place: a collective investigation of place, but not as we know it One of the ways that In Certain Places has attempted to address, or at least question the status of artistic research, is through its Practising Place project. Between 2013 and 2016, ten artists whose work deals with aspects of place - including rural mythologies, language, nostalgia, typography, architecture, virtual places and urban noise - were invited to form partnerships with academics from U.K. universities, all sharing a similar research focus. Through a series of informal conversations and email exchanges, these artist-academic partners discussed their individual interests, methods and approaches, culminating in a series of public in-conversation events throughout the North of England, a collection of essays published on a popular art and culture website, a forthcoming book and a number of independent collaborations. ${ }^{109}$

By promoting what academic-curator Cameron Cartiere described as conversation as "a method of exploration", 110 which begins with one-to-one exchanges, and gradually expands to encompass other voices and experiences, Practising Place conferred equal status to academic research, art practice and personal experience, and an amalgamation of intrinsic, instrumental and institutional values, ${ }^{111}$ within a collective investigation of place. In so doing, it encouraged artists to examine how they might learn from, challenge or contribute to traditional understandings of knowledge production, whilst freeing academics to pursue more creative research methods.

In boosting the relationships between public art practice and academia, UCLan provides a master's practice-based course, associated with In Certain Places, wherein many of the methods and skills as used for creating work in response to a place are transferred to students. The majority of the students are from the local area, so this feeds into the wider arts ecology in Lancashire. In addition, In Certain Places often commissions graduates as part of its main programme.

After more than a decade of generating an appetite for public art in Preston, In Certain Places' recent move to the university appears like a new beginning, with an underlying sense of déjà-vu. As in its early days, the wider context for the programme 
is one of regeneration, both in relation to the new university campus masterplan 2015$2025^{112}$ and its current involvement in the Preston and Lancashire City Deal - a multimillion-pound infrastructure scheme focused on the city's rural fringes. ${ }^{113}$ The challenge for the programme, therefore, is how to continue to foster intrarelationships amongst campus communities and inter-relationships between the university and city, whilst resisting the type of instrumentalisation, which, although conducive to funding, can stifle critical art practice.

\section{BUILDING AND SHARING PUBLICS: AMBITIONS AND FRICTIONS}

This article has stressed the advantages of conducting comparative and interinstitutional collaborative research on analysing how public campus art connects the university, publics (i.e. communities of interest) and the city. The analysis has particularly called attention to gauging the "success" of campus art along topical complexities and tensions that are part and parcel in the choices of the nature of the artwork (e.g., permanent vs. temporary, material vs. process- or digital-based), its curatorial and preservational aspects, and the relationships amongst artists, members of the university, local authorities and private partners.

Based on case studies on the Public Art Strategy (2015-present) of the University of Leeds in relation to the long-duration public art initiative In Certain Places (2003-present), as mediated through the University of Central Lancashire (UCLan) in Preston, U.K., this article has arrived at two broad comparative conclusions on how public art has been (re)made on campus, and beyond, and how the university, publics and the city have been interconnected accordingly in the context of these cases:

(1) While In Certain Places has so far been strongly focusing on bringing the university into the city, the Leeds Public Art Strategy has hitherto been vigorously committed to promoting the campus as a public space worth visiting and exploring through the modus of public art and, in so doing, attracting wide audiences from the city and region.

(2) The Leeds Public Art Strategy has actively encouraged different forms of public engagement with foremostly the university's permanent public artworks (and as such the wider campus), whereas In Certain Places has commissioned primarily temporary public artworks as a means to create new connections between different communities within the city, including the university.

Above broad and somewhat generalising contrasting conclusions are not exhaustive and do not reflect the differentiated and ambiguous public art practices in both localities. Also, the programmes may have different accents in keeping with any (unanticipated) changes to campus development plans and managerial priorities. Particularly, the tack of In Certain Places might converge with the Leeds Public Art Strategy, considering UCLan's masterplan to market the campus as a public space, too.

The public functions of public art, in the phraseology of the art historian Cher Krause Knight, should be understood along "the interrelationships between content [which includes both object and intentions] and audience; what art has to say, to whom it speaks, and the multiple messages it may convey." 114 The analysis on public art-led development across the campuses of Leeds and Preston has revealed that the relationship between content (as especially inherent in the university's own agendas) and audience is highly convoluted, bearing in mind the "multi-positional" fabric of what institutions of higher education and research have come to embody. They are 
increasingly expected to shoulder accountabilities towards not only the academe and its staff, student and alumni communities, but also towards university management and estates - as well as non-specialist audiences, local authorities, commercial sector parties, members of the publics, governments, funders, and many others. In this regard, we set forth three concluding afterthoughts.

First, there is some disunity or discrepancy between desired images, written discourse and claims, and actual practices and deliverables. It is this multifaceted reality of public campus art practice and its immanent fragmented spaces, yet creative potentials for engagement, which problematises both content and audience. In this sense, the Leeds and Preston cases endorse Hards et al.'s observation of the disharmony in approaching public art as resource for both "the university" and the "wider community" in that ...

public art strategies reveal the complexities and pragmatic considerations universities face when determining levels of access, the definition of spaces and activities that take place in them, and even in recognising and defining their multiple communities. ${ }^{115}$

Second, coming from a legacy largely focused on individually commissioned pieces, the University of Leeds with the Public Art strategy has sought to make large strides in broad public engagement with art on campus and beyond. As noted by Hards et al., universities are coping with higher-order, imposed "confusions" of impactrelated expectations for community engagement and for higher research and education marketing (and the attendant competition for generating income). Here, public art's instrumental values have been more strongly emphasised than intrinsic or institutional core values. ${ }^{116}$ Despite various issues such as challenged budgets and staff capacity, universities - as especially seen in the Leeds examples - can ensure reasonable resources for providing the continuity of developing public art practice on/via campus in concerted action with university staff and students, users of campus space and participants in university life, everyday residents, as well as public and private partners and funders in the city and beyond. This would make public art practice more integral to university life and the civil society.

Third, contrary to the Leeds case, for In Certain Places - a programme with as yet no core funding or long-term institutional support - precariousness has appeared as a source of anxiety. Yet, paradoxically, uncertainty has also allowed the programme to achieve the things it has. Curator Claire Doherty describes public art as "a gathering point and catalyst for change" which, unlike fixed-term institutional strategies allows "collaborative ideas to develop over time, leaving room for the unplanned". ${ }^{117} \mathrm{By}$ filling the void of the city's failed regeneration scheme with more flexible possibilities, In Certain Places helped to initiate a culture of creativity within Preston city centre. In the same way, by continuing to occupy a space between the university and city, the programme is well placed to generate new forms of collective action, aspiring after bridging the gaps between art, academia and everyday life and encouraging new understandings and approaches to the future of campus space, and farther.

\section{RESEARCH AGENDAS}

The article's analyses of the Leeds and Preston cases have identified some special areas in both research and practice for attending more thoroughly to how curating, (re)making and experiencing public art on campus can be advanced. What all of the 
previous calls for is a place-based strategy in engaging audiences with campus art. ${ }^{118}$ The opportunities and limitations for engagement are subsistent in issues such as conflicting academic, artistic and property development interests, tight budgets and difficult relationships with funders. Methodological frameworks and resources (including time and funding) for such thorough engagement and (e)valuation thereof, in order to develop evidence-based policies, remain particularly thin and need further attention. The lack of financial resources is symptomatic of public art practice more generally, all the more so considering that the U.K.'s recent decision to leave the European Union and subsequent political upheaval threatens a return of the economic instability that characterised much of the late 2000 s.

This study encourages future work to expand on how ephemeral public artwork, and attendant fleeting practices and public engagements, might be in a potentially stronger position to play along with the social dynamics of very diverse and changing campus places and as such integrate the academy with diverse communities - rather than fetishising permanent and material output and "canonical" public art production by established artists. Students comprise the campus population's lion's share, although specially their input in public art practice should be both further deepened and researched - also in regard to potential educational benefits. On the latter, further work is needed on how public art practice might reinforce curriculums.

Campus spaces are progressively more recognised as open public spaces for engagement beyond members of the university alone, where a particular challenge remains to reactivate underused spaces. ${ }^{119}$ There appear various restrictive policies and practices, such as health and safety regulations that limit public participation, and security measures (e.g., events with staff-/student-only admission) which curb wider public access. So, how might public art practice improve the harmony between instrumental strategies and authentic engagements, between campus and city developments, as well as between members of the university and citizens beyond? And how can such "holistic" engagement ${ }^{120}$ be stretched to embrace collaborative publicart practices across universities in the country, having wide public engagement as corollary?

As final note and response to recent calls in public art research for attending to how new prospects of the emerging digital age and media technologies pose new opportunities for bridging publics, ${ }^{121}$ research and practice are particularly encouraged to explore the possibilities and limitations of digital technologies for engaging people with public campus art in ways that break with traditional, oftsculpture-oriented conducts and toolkits - as well as for documenting its legacy for future generations and campus-user audiences. The Leeds and Preston campuses have made some notable steps towards reaching out to online audiences about the presence and archives of their public artworks produced on/via campus. Yet, all-out efforts are needed to incorporate the digital as integral experience of what public art does and can do in multi-user, online/offline environments. There is an exciting university/universe in the offing.

\section{ACKNOWLEDGEMENTS}

The authors are grateful to the Editors of Public Art Dialogue and anonymous reviewers for their constructive feedback that helped to strengthen this article. 


\section{BIBLIOGRAPHY}

Bishop, Claire. Artificial Hells: Participatory Art and the Politics of Spectatorship. London: Verso Books, 2012.

Cartiere, Cameron. Re/Placing Public Art: The Role of Place-Specificity in New Genre Public Art. Saarbrücken: VDM Verlag Dr. Müller, 2010.

Cartiere, Cameron, and Martin Zebracki, eds. Everyday Practice of Public Art: Art, Space, and Social Inclusion. London: Routledge, 2016.

Crouch, Amelia. "'Public' Art on Campus: Strategy and Reality in U.K. Universities." https://www.a-n.co.U.K./news/public art-on-campus-strategy-and-reality-inU.K.-universities (accessed 30 Aug. 2016).

De Certeau, Michel. The Practice of Everyday Life, Trans. Steven Rendall. Berkeley, CA: University of California Press, 1984.

Doherty, Claire, ed. Out of Time, Out of Place: Public Art (Now). Art Books: London, 2015.

Gumprecht, Blake. "The Campus as a Public Space in the American College Town." Journal of Historical Geography 33.1 (2007): 72-103.

Hansen, Tone. "Everything That Is Temporary Must Be Removed." Geist 11,12,14 (2007-2008): 30-41.

Hards, Lorna, Sian Vaughan, and James Williams. "Place-Making and Other Purposes: Public Art on Campus". In The Physical University: Contours of Space and Place in Higher Education. Ed. Paul Temple. New York, NY: Routledge, 2014. 106-128.

Holden, John. Cultural Value and the Crisis of Legitimacy. London: Demos, 2006.

Maharaj, Sarat. "No-How: Stopgap Notes on 'Method' in Visual Art as Knowledge Production." Geist 11,12,14 (2007-2008): 127-137.

Orr, David. Earth in Mind: On Education, Environment and the Human Prospect. Washington, DC: Island Press, 2016.

Pollock, Venda, and Ronan Paddison. "On Place-Making, Participation and Public Art: the Gorbals, Glasgow." Journal of Urbanism: International Research on Placemaking and Urban Sustainability 7.1 (2014): 85-105.

Quick, Charles, Elaine Speight, and Gerrie Van Noord, eds. Subplots to a City: Ten Years of In Certain Places. Preston: In Certain Places, 2014.

Shalgosky, Sarah, and Michael Tooby, eds. Imagining a University: Fifty Years of The University of Warwick Art Collection. Warwick: Mead Gallery, University of Warwick.

Stevens, Quentin. The Ludic City: Exploring the Potential of Public Spaces. London: Routledge, 2007.

\section{NOTES}

\footnotetext{
${ }_{1}$ After Malcolm Miles, Art, Space and the City (London: Routledge, 1997); Martin Zebracki, "Beyond Public Artopia: Public Art as Perceived by its Publics," GeoJournal 78.2 (2013): 303-317.

2 For public art's polemic "public" nature, see Hilde Hein, Public Art: Thinking Museums Differently (Oxford: Altamira, 2006), and Martin Zebracki, "A Cybergeography of Public Art Encounter: The case of Rubber Duck," International Journal of Cultural Studies (2016). DOI: 10.1177/1367877916647142.

3 See Lorna Hards, Sian Vaughan, and James Williams, "Place-Making and Other Purposes”; and Zebracki, "A Cybergeography of Public Art Encounter.”
} 
4 National Co-Ordinating Centre for Public Engagement, "What Is Public Engagement?," https://www.publicengagement.ac.U.K./explore-it/what-publicengagement (accessed 30 Aug. 2016).

5 See David Watson, Managing Civic and Community Engagement (Maidenhead: McGraw-Hill/Open University Press, 2007).

${ }^{6}$ Hards et al., 106.

7 See Stella Butler, "A Public Art Strategy for the University of Leeds," https://library.leeds.ac.U.K./downloads/file/695/public_art_strategy (accessed 30 Aug. 2016).

${ }^{8}$ See Charles Quick, Elaine Speight, and Gerrie Van Noord, Subplots to a City.

9 See Claire Robinson, and Neil Adams, "Unlocking the Potential: The Role of Universities in Pursuing Regeneration and Promoting Sustainable Communities," Local Economy 23.4 (2008): 277-289.

${ }^{10}$ See Hards et al.

${ }^{11}$ For example, see research impact case study "Public Art, Culture and the Regeneration of Place of the Leeds Metropolitan University," http://impact.ref.ac.U.K./CaseStudies/CaseStudy.aspx?Id=18931 (accessed 30 Aug. 2016). This was submitted to the Research Excellence Framework (http://www.ref.ac.U.K.), a national new system for assessing research quality in U.K. higher education institutions. The study was primarily based on David Usher and Ian Strange, "Evaluating public art in the North of England: Logic models, frameworks and emerging impact," Local Economy 26.3 (2011): 203-213.

12 Alex Buxton, "Post-War Public Art - New Listings," http://www2.warwick.ac.U.K./newsandevents/pressreleases/university_of_warwick 146s_post-war_public_art_protected1/ (accessed 30 Aug. 2016); for particularly useful key works on campus art, see Imagining a University, edited by Sarah Shalgosky and Michael Tooby, and Hards et al. for a thought-provoking comparison between U.K. public art practice on the campuses of Oxford Brookes University, Durham University, University of Birmingham, University of Warwick, University of Bristol, North West Cambridge, Robert Gordon University and Anglica Rusking University - which we expand by our analyses on the Leeds and Preston cases.

${ }^{13}$ See Sarah Selwood, "Freedoms and Constraints," in Imagining a University, 71-79.

${ }^{14}$ See Beth Williamson, "Becoming a Collection," in Imagining a University, 41-49; see also Lynn Pearson, Public Art Since 1950 (London: Shire Publications, 2008).

${ }^{15}$ Hards et al. discuss Oxford Brooks University as a salient site for traditional, sculpture-based public art making.

16 Williamson.

17 Historic England, "Public Art (Sculpture) 1945-1985," https://historicengland.org.U.K./whats-new/listing/public-art-sculpture/ (accessed 30 Aug. 2016).

${ }_{18}$ Photograph of $3 B$ Series No. 1 at http://www2.warwick.ac.U.K./services/communications/medialibrary/images/dece mber2015/red_square_early_1970s.jpg (accessed 30 Aug. 2016).

19 Also the universities of Bristol, North West Cambridge and Leeds are strongly concerned with public art collection building - see Hards et al.

20 Photograph and artwork details of $A$ Celebration of Engineering Sciences at https://www.google.com/maps/d/viewer?mid=1CaKa8iq54NFksTjVa-Xi14Rv1eQ (under Leeds red pin) (accessed 30 Aug. 2016).

${ }^{21}$ Ibid.

${ }^{22}$ Selwood, 78-79.

${ }^{23}$ Amelia Crouch, "Public' Art on Campus." 
24 See Hards et al.

25 See Liljenwall, Sandra, "Exploring Best Practices for Building a University's Public Art

http://digitallibrary.usc.edu/cdm/ref/collection/p15799coll127/id/66345

(PhD thesis, 2008) (accessed 30 Aug. 2016).

${ }^{26}$ See Laurel Logue, "Representative Policies for Displaying Art in Student Union Galleries and Public Spaces in the United States," https://vtechworks.lib.vt.edu/handle/10919/31814 (MA thesis, 1999) (accessed 30 Aug. 2016).

27 Loughborough University Arts, "Radar: Artists Engage with Research," http://www.arts.lboro.ac.U.K./radar (accessed 30 Aug. 2016).

28 Loughborough University, "Our research and impact," http://www.lboro.ac.U.K./research/our-research/case-

studies/maximisingthesocialandculturalbenefitsofpublicart/ (accessed 30 Aug. 2016); Hards et al. discuss Robert Gordon University where also strong attempts have been made at community-focused public art engagement, emphasising transparent communication.

29 Ibid.

30 Bishop, Artificial Hells.

${ }^{31}$ See Brad Love, "Using Campus Art to Build Relationships," College Teaching 61.4 (2013): 150.

32 See Donald Kuspit, "The Artist and the University: The Meaning of their Incompatibility," The Centennial Review 35.1 (1991): 21-30.

33 See Eleanor Nairne, "Collecting Thoughts: On Artangel and the University of Warwick," in Imagining a University, 93-118.

34 Sarah Shalgosky and Stephanie James, "The Renaissance of University Galleries?," in "What Is to Be Done?": Cultural Leadership and Public Engagement in Art and Design Education, eds. Steve Swindells and Anna Powell (Newcastle upon Tyne: Cambridge Scholars Publishing, 2014), 29-36.

35 Crouch.

${ }^{36}$ Holden, Cultural Value and the Crisis of Legitimacy.

37 Sarah Shalgosky, "Fifty Years On: Re-Imagining the Art Collection," in Imagining a University, 119-146.

38 The instrumental value of social inclusion deserves much attention in recent public art research, see Cameron Cartiere and Martin Zebracki, eds. Everyday Practice of Public Art.

39 See Carl Grodach, "Art Spaces, Public Space, and the Link to Community Development," Community Development Journal 45.4 (2009): 474-493; and Love. 40 Shalgosky, 125-126; see also Daphne Dawn and Mei-Yuan Chao, "The Responsive Roles of Campus Art Museums/Galleries in Urban Public Universities: A Case Study of Organizational Adaptation," http://scholarship.shu.edu/cgi/viewcontent.cgi?article $=2854 \&$ context=dissertations (PhD thesis, 2013) (accessed 30 Aug. 2016).

${ }^{41}$ Sian Vaughan in Crouch.

42 Petherbridge, Deanna, Art for Architecture: A Handbook on Commissioning (London: HMSO, 1987).

43 See Pollock and Paddison, "On Place-Making, Participation and Public Art”.

44 Ibid.

45 See Kuspit, "The Artist and the University."

46 Williamson, "Becoming a Collection"; see also Liljenwall for "best practices", albeit in the U.S. context. 
47 See Shalgosky.

48 See Hards et al. (112 -114), critically discussing how the University of Birmingham uses its Public Art Trail as "marketing tool".

49 See Jill Cirasella and Miriam Deutch, "From Art on the Wall to Something for All: How an Academic Library Turned Its Art Collection into a Campus Attraction," http://academicworks.cuny.edu/cgi/viewcontent.cgi?article=1011\&context=gc_pub (accessed 30 Aug. 2016); and Terry Zeller, "The Role of the Campus Art Museum," Curator: The Museum Journal 28.2 (1985): 87-95.

50 The public art strategies of the universities of Durham and Bristol are strongly focused on "offerings" of cultural sustainability - see Hards et al.

${ }^{1}$ See Beth Perry, Karen Smith, and Saskia Warren, "Revealing and Re-Valuing Cultural Intermediaries in the 'Real' Creative City: Insights from a Diary-Keeping Exercise," European Journal of Cultural Studies 18.6 (2015): 724-740.

$5^{2}$ See Carole Beere, James Votruba, and Gail Wells, Becoming an Engaged Campus: A Practical Guide for Institutionalizing Public Engagement (San Francisco, CA: Jossy-Bass/Wiley), 2011.

53 Crouch; see also Michael Grenier, "An Analysis of Public Art on University Campuses: Policies, Procedures, and Best Practices," http://conservancy.umn.edu/bitstream/handle/11299/57637/Grenier_umn_o13oE _10802.pdf?sequence $=1$ (PhD thesis, 2009) (accessed 30 Aug. 2016).

54 See Grenier.

55 See Cartiere and Zebracki.

${ }^{56}$ Gumprecht, 72. This argument has been made in regard to the US context, but in the authors' assessment it may be well applicable to the U.K. context.

57 Crouch.

58 See Hards et al.

59 See Stevens, The Ludic City.

60 See John Freeman and Mimi Sheller, "Editors' Statement: Hybrid Space and Digital Public Art," Public Art Dialogue 5.1 (2015): 1-8.

${ }^{61}$ Orr, Earth in Mind, 14, cited in Williamson, 48.

62 See Tom Kelly, "Feature: Building a Sustainable Learning Community at the University of New Hampshire," The Declaration 6.2 (2003). http://www.ulsf.org/pub_declaration_othvol62.htm (accessed 30 Aug. 2016), in reference to Orr, Earth in Mind.

63 De Certeau, The Practice of Everyday Life.

64 Williamson.

65 Shalgosky, 119.

66 See Alan Powers, "The University of Warwick: The Architect, the Collector and the Patron," in Imagining a University, eds. Sarah Shalgosky and Michael Tooby, 17-40. 67 Shalgosky, 119.

68 Nigel Thift, "Foreword," in Imagining a University, eds. Sarah Shalgosky and Michael Tooby, 7.

69 "Curating the Campus Symposium programme, 11 Jun. 2015," https://library.leeds.ac.U.K./downloads/file/689/curating_the_campus_symposiu m_programme (accessed 30 Aug. 2016).

${ }_{70}$ "The importance of public art," The Yorkshire Post, 10 Apr. 2015. http://www.yorkshirepost.co.U.K./news/the-importance-of-public-art-1-7202949 (accessed 30 Aug. 2016).

${ }^{71}$ See http://www.contemporaryartsociety.org/about (accessed 30 Aug. 2016).

${ }^{72}$ See also Imagining a University, eds. Sarah Shalgosky and Michael Tooby.

73 See Hards et al. 
74 "Public Art on Campus, University of Leeds," https://library.leeds.ac.U.K./publicart with Campus Art Trail map at https://library.leeds.ac.U.K./downloads/file/803/public_art_trail_2016 (accessed 30 Aug. 2016).

75 For the detailed University of Leeds campus map, see https://www.leeds.ac.U.K./campusmap (accessed 30 Aug. 2016).

${ }_{76}$ The authors reckon such central public art administration and curation, as seen at many U.S. universities, as fairly unusual in the British context, which makes public art management substantially more feasible than the situation at some universities where different departments own public art works.

77 The Stanley \& Audrey Burton Gallery, "Christ driving the Moneychangers from the TempleChrist driving the Moneychangers from the Temple," https://library.leeds.ac.U.K./art-gallery-explore/247 (accessed 30 Aug. 2016). 78 Shalgosky, "Fifty Years On"; Holden, Cultural Value and the Crisis of Legitimacy. 79 See search engine of the University of Leeds Art Collection at https://library.leeds.ac.U.K./art-gallery-collections (accessed 30 Aug. 2016). 80 Butler.

81 Photograph and artwork details of $A$ Sign for Art at https://library.leeds.ac.U.K./art-gallery-

explore/391678/sign_for_art_stelae_2014?query=Wilson\%2C\%20Keith\&resultOffs et $=1$ (accessed 30 Aug. 2016).

82 See Art Council England's comment on the Yorkshire Year of the Textile at https://www.leeds.ac.U.K./news/article/3872/year-

long_celebration_of_textiles_finds_a_common_thread_for_arts (accessed 30 Aug. 2016).

83 Ibid. for further details of the Yorkshire Year of the Textile.

84 Hards et al. discuss the art-technology nexus in regard to Anglia Ruskin University's Visualise Programme, instigating collaborative public art making aimed at involving partners and impacting venues beyond the campus.

85 Interview with Simon Fujiwara by Lisa Le Feuvre, Head of Sculpture, Henry Moore Institute at the Curating the Campus Symposium, 11 June 2015.

${ }^{86}$ Hards et al., 126.

87 Hards et al., 125 .

88 See video capture of Man Made Fibres: A Dance Response (2016) by TurveyWorld at https://vimeo.com/174176138 (accessed 30 Aug. 2016).

89 See Hards et al.

9o Mitzi Cunliffe's Man-Made Fibres Commission in Context, exhibition curated by Ann Sumner at The Stanley \& Audrey Burton Gallery, 2016.

${ }^{91}$ See Martin Zebracki, Rob Van der Vaart, and Irina Van Aalst, "Deconstructing Public Artopia: Situating Public-Art Claims Within Practice," Geoforum 41.5 (2010): 786795 .

92 "British Art Show 8,"

http://www.leeds.gov.U.K./museumsandgalleries/Pages/leedsartgallery/BritishArt-Show-.aspx (accessed 30 Aug. 2016).

93 "Unfold Leeds - British Art Show 8," http://www.tigertea.co.U.K./portfolio/unfold-leeds/ (accessed 30 Aug. 2016).

94 Since its inception, In Certain Places has been funded on a project-by-project basis by the Arts Council of England's Grants for the Arts Scheme. It also receives ad hoc funding for particular projects, as well as support-in-kind, from Preston City Council and the University of Central Lancashire. It is currently in receipt of three-year 
funding from the city council to develop a programme of activities as part of their City Deal infrastructure scheme.

95 See In Certain Places, "Projects," http://incertainplaces.org/projects/\# (accessed 30 Aug. 2016).

96 This was part of a speech given by Preston City Council Chief Executive, Lorraine Norris, at the launch of the book Subplots to a City: Ten years of In Certain Places at the Harris Museum and Art Gallery, Preston, Feb. 2015.

97 For the detailed campus map of the University of Central Lancashire, see https://www.uclan.ac.U.K./visit/assets/preston_city_campus_map.PDF (accessed 30 Aug. 2016).

98 See Hards et al.

99 Further details about Harris Flights at http://incertainplaces.org/projects/harrisflights/ (accessed 30 Aug. 2016).

100 Rod Dubrow-Marshall, cited in Quick et al., 37.

${ }^{101}$ Further details about The People's Canopy at http://peoplescanopy.info (accessed 30 Aug. 2016).

102 Further details about Homing at http://incertainplaces.org/projects/homing/ (accessed 30 Aug. 2016).

103 Further details about Manual Labours at http://www.manuallabours.co.U.K./about/ (accessed 30 Aug. 2016).

104 Further details about When is a Star a Star? at http://www.bonniecraig.com/blog/lsf (accessed 30 Aug. 2016).

105 See Holden.

${ }^{106}$ Hansen, "Everything That Is Temporary Must Be Removed", 32.

107 Maharaj, "No-How", 128.

108 See Shalgosky.

109 Further details about the Practising Place programme at http://practisingplace.org (accessed 30 Aug. 2016).

110 Cartiere, Re/placing Public Art, 29.

${ }^{111}$ See Holden.

${ }^{112}$ See University of Central Lancashire, "University of Central Lancashire Masterplan Framework,"

http://www.uclan.ac.U.K./masterplan/assets/uclan_masterplan_report_web.pdf (accessed 30 Aug. 2016).

113 See Preston City Council, "Preston and Lancashire City Deal," http://www.preston.gov.U.K./businesses/preston-and-lancashire-city-deal (accessed 30 Aug. 2016).

114 Cher Krause Knight, Public Art: Theory, Practice and Populism (Oxford:

Blackwell), 2008, viii.

115 Hards et al., 125-126.

116 See Holden.

117 Doherty, Out of Time, Out of Place, 11-13.

118 See Orr.

${ }^{119}$ See Gumprecht, "The Campus as a Public Space in the American College Town."

120 See Nairne.

121 See Freeman and Sheller; and Zebracki, "A Cybergeography of Public Art Encounter"; see also Hards et al., who discuss the effective use of digital media technologies to engage publics in public art practice on the Anglia Ruskin University campus. 


\section{BIBLIOGRAPHICAL NOTES}

Martin Zebracki is Lecturer in Critical Human Geography at the University of Leeds. His research sits at the crossroads of public art, social engagement and (sexual) citizenship in contemporary contexts of western cities. His recent work includes the anthology The Everyday Practice of Public Art: Art, Space, and Social Inclusion (edited with Cameron Cartiere, Routledge, 2016). Academic profile: http://www.zebracki.org.

Ann Sumner is Head of Cultural Engagement at the University of Leeds where she leads the Public Art Strategy. She has wide experience of cultural management and was previously Director of the Barber Institute of Fine Arts and Professor of Fine Art and Curatorial Practice, University of Birmingham and Head of Fine Art at the National Museum of Wales, Cardiff.

Elaine Speight is a Research Fellow in the School of Art, Design and Fashion at the University of Central Lancashire, Preston, U.K., where she co-curates In Certain Places - a programme of artistic interventions and events, which examines how artists can contribute to the form and functions of a place, by exploring new approaches to art, culture and urban development (http://www.incertainplaces.org). 